\title{
Respiratory viruses and exacerbations of asthma in adults
}

\author{
Karl G Nicholson, Julie Kent, Deborah C Ireland
}

\begin{abstract}
Objective-To study the role of respiratory viruses in exacerbations of asthma in adults.

Design-Longitudinal study of 138 adults with asthma.

Setting-Leicestershire Health Authority.

Subjects -48 men and 90 women 19-46 years of age with a mean duration of wheeze of $19 \cdot 6$ years. $75 \%$ received regular treatment with bronchodilators; $89 \%$ gave a history of eczema, hay fever, allergic rhinitis, nasal polyps, or allergies; $38 \%$ had been admitted to hospital with asthma.

Main outcome measures-Symptomatic colds and asthma exacerbations; objective exacerbations of asthma with $\geqslant 50 \mathrm{Vmin}$ reduction in mean peak expiratory flow rate when morning and night time readings on days 1-7 after onset of symptoms were compared with rates during an asymptomatic control period; laboratory confirmed respiratory tract infections.
\end{abstract}

Results-Colds were reported in $80 \%(223 / 280)$ of episodes with symptoms of wheeze, chest tightness, or breathlessness, and $89 \%$ (223/250) of colds were associated with asthma symptoms. $24 \%$ of 115 laboratory confirmed non-bacterial infections were associated with reductions in mean peak expiratory flow rate $\geqslant 50 \mathrm{~V} / \mathrm{min}$ through days 1-7 and $48 \%$ had mean decreases $\geqslant 25 \mathrm{~V} / \mathrm{min} .44 \%$ of episodes with mean decreases in flow rate $\geqslant 50 \mathrm{~V} / \mathrm{min}$ were associated with laboratory confirmed infections. Infections with rhinoviruses, coronaviruses OC43 and $229 E$, influenza $B$, respiratory syncytial virus, parainfluenza virus, and chlamydia were all associated with objective evidence of an exacerbation of asthma.

Conclusions-These findings show that asthma symptoms and reductions in peak flow are often associated with colds and respiratory viruses; respiratory virus infections commonly cause or are associated with exacerbations of asthma in adults.

\section{Introduction}

Research into the effects of respiratory viral infections in chronic lung disease has been hampered by difficulties in identifying respiratory pathogens. Human rhinoviruses, the major causative agents of the common cold, are fastidious for certain cells and growth conditions, and the large numbers of recognised serotypes-in excess of 100-precludes serology for epidemiological studies. Human respiratory coronaviruses, which are second in importance in causing colds in adults, are also fastidious and serological tests are not widely available. Accordingly, rates of virus identification during acute respiratory infections have remained low, especially in adults. Two comparable prospective studies of asthmatic patients identified viruses in $55 \%$ of symptomatic respiratory tract infections in children under 11 years of age ${ }^{1}$ but in only $26 \%$ of such infections in subjects aged 3-60 years. ${ }^{2}$

Studies in children with asthma or wheezy bronchitis have shown that $38-49 \%$ of wheezy episodes are associated with respiratory viruses, ${ }^{3-5}$ but in adults virus and mycoplasma infections were identified in only
$19 \%,{ }^{6}$ and virus identification rates were $10 \%$ in two further studies. ${ }^{78}$ However, the percentage of laboratory confirmed viral infections that resulted in exacerbations of asthma was similar in the one study of adults with asthma $(60 \%)^{8}$ to those reported for children $(48-53 \%){ }^{24}$ The weak association between asthma and upper respiratory tract infection suggested by previous epidemiological studies of adult asthmatics could have been due to difficulties in isolating human rhinoviruses and human coronaviruses.

We have used enzyme linked immunosorbent assays (ELISAs) for antibodies to human coronaviruses of groups $229 \mathrm{E}$ and OC43 in previous studies. ${ }^{911}$ Evidence of human coronavirus infection was obtained in 7-19\% of paired serum samples from patients with upper respiratory tract infections. In addition, we found seminested reverse transcriptase polymerase chain reactions to be five times more sensitive than cell culture in detecting human rhinoviruses in samples from adults with respiratory virus infections." Accordingly we thought that applying these diagnostic methods to clinical samples from adult asthma patients with symptoms of colds or asthma would lead to a better appreciation of the role of viruses in asthma in adults.

\section{Methods}

PATIENTS

We studied 138 adults with asthma, defined as recurrent episodes of reversible wheezing and breathlessness. ${ }^{12}$ There were 48 men and 90 women 19-46 years of age (mean age 32.7 years) and their mid-morning mean peak expiratory flow rate on recruitment was $94 \cdot 6 \%$ predicted (range $37 \cdot 4-134 \cdot 3 \%$; SD $19 \cdot 1 \%$ ). The mean duration of wheeze was 19.6 $(1-43 ; 11.7)$ years. A total of $103(75 \%)$ subjects were taking regular treatment with bronchodilators; 123 $(89 \%)$ gave a history of eczema, hay fever, allergic rhinitis, nasal polyps, or allergies; and $53(38 \%)$ had been admitted to hospital for an asthmatic attack. Thirteen $(9 \%)$ were smokers. Thirteen patients were recruited through the pulmonary function laboratory and chest physicians; 22 through an allergy clinic; 44 through general practitioners with age, sex, and disease registers; 49 made telephone requests to the trialists after seeing a newspaper article about the study; and 10 responded to posters advertising the study. Volunteers gave written informed consent to the protocol which was approved by the Leicestershire Health Authority ethics committee.

\section{THE STUDY}

The study ran from October 1990 to August 1992 and there was rolling recruitment to and exit from the study. Subjects were asked about the duration and frequency of their asthma, medication, hospitalisation, and history of atopy; they were examined clinically; peak expiratory flow rates were measured three times with a mini-Wright peak flow meter; and a baseline blood sample and nose and throat swabs were collected for serology and virological testing. Thereafter the subjects kept a daily diary of peak expiratory flow rate, which was measured twice daily, immediately on rising in the morning (before bronchodilator use) and just 
before going to bed; the best of three measurements was recorded. Subjects were instructed to contact the trialists by telephone or answerphone immediately they developed symptoms of an acute upper respiratory tract infection or increased symptoms of chest tightness or wheezing or breathlessness, and to keep a daily diary of the symptoms printed on the reverse of the flow rate diary during symptomatic episodes. Clinical assessment of upper respiratory symptoms followed a modification of the Common Cold Unit's standard protocol. ${ }^{1013}$ Respiratory symptoms were scored as absent, mild, moderately severe, and severe (box). Details of antibiotic use, bronchodilator use, medical consultations, and hospital admissions were also recorded. Symptomatic patients were seen at home or at work as soon as possible after the onset of symptoms and underwent examination of the oropharynx, neck, and chest. Nose and throat swabs and an acute phase $10 \mathrm{ml}$ blood sample were collected during this visit, and a convalescent $10 \mathrm{ml}$ blood sample was collected approximately 21 days later. All subjects were seen routinely every three months; during these visits a $10 \mathrm{ml}$ blood sample and nose and throat swabs were collected.

\section{VIROLOGY}

Nasal swabs were placed high in the anterior nares and throat swabs were passed firmly over the pharynx and tonsils. Swabs were immediately placed together in $2.5 \mathrm{ml}$ of nutrient broth containing virus transport medium $(10 \%$ fetal calf serum, penicillin, streptomycin, and amphotericin B) and were stored at $-70^{\circ} \mathrm{C}$, usually within several hours of collection and always within 12 hours. Paired acute and convalescent serum samples were stored at $-20^{\circ} \mathrm{C}$ and tested later by complement fixation tests for antibodies to adenovirus; influenza $\mathrm{A}$ and $\mathrm{B}$; respiratory syncytial virus; parainfluenza viruses types 1,2, and 3; Mycoplasma pneumoniae; and Chlamydia psittaci. A fourfold rise in antibody was taken as indicating infection. An enzyme linked immunosorbent assay (ELISA) not commercially available was used to detect rises in antibodies to coronavirus $229 \mathrm{E}$ and OC43. ${ }^{14}$ Serum samples were tested at a dilution of 1:200, and a consistent ratio of $\geqslant 1.3$ between absorbance values of convalescent and acute samples was taken as indicating recent infection.

For virus isolation $0 \cdot 2 \mathrm{ml}$ volumes of nose and throat swabs in virus transport medium were inoculated onto

\section{Classification of symptomatic episodes}

Symptom diary cards asked patients to score symptoms as $0=a b s e n t, 1=$ mild, 2-moderately severe, and 3=severe for these categories: runny nose, stuffy nose, sneezing, sore throat, hoarseness, red or watery eyes, face ache or earache, feeling unwell, muscle aches, chills, cough, painful swollen neck glands, increased use of hankies, chest tightness, wheeze, and breathlessness.

\section{Clinical classification}

Doubtful cold

Cold

Subjective exacerbation of asthma

Cold with asthma

Doubtful cold plus asthma

\section{Clinical events}

Symptoms scoring no more than 1 (mild) or in only one of categories nose, throat, and cough

Symptoms of two or more of the categories nose, throat, cough, and systemic features, with at least one symptom scoring 2 (moderately severe) or more

Increase in one or more symptoms of wheeze, chest tightness, and breathlessness in association with an increase in bronchodilator use; or subject was noted to be wheezing on clinical examination; or subject was admitted to hospital for asthma

Symptoms of cold and subjective exacerbation combined

Symptoms of doubtful cold and subjective exacerbation of asthma together monolayers of Ohio HeLa, MRC-5, C16, and MDCK cells. All cell lines were cultured in roller tubes at $33^{\circ} \mathrm{C}$ with $5 \%$ carbon dioxide and observed for 14 days. Specimens inoculated onto Ohio HeLa cells were routinely passaged once after seven days, and specimens giving equivocal results were passaged up to three times. Human rhinovirus infection was diagnosed by observation of characteristic cytopathic effect, characteristic acid lability at $\mathrm{pH} 3$, and inhibition of cytopathic effect at $37^{\circ} \mathrm{C}$.

Human rhinoviruses (HRV) in nose and throat swabs were also identified by using a seminested reverse transcriptase (RT) polymerase chain reaction (PCR) that incorporated a touchdown reaction cycle ${ }^{15}$ and is described fully elsewhere. ${ }^{11}$ The primers and probes used had the following sequences:

$\begin{array}{ll}\text { RT } 1{ }^{\circ} \mathrm{PCR}- & \text { s'CGGACACCCAAAGTAG3' } \\ \text { PCR }+ & { }^{5} \text { GCACTTCTGTTTCCCC3' } \\ \text { HRV 2 } 2{ }^{\circ} \text { PCR - } & \text { 5'GGCAGCCACGCAGGCT3' } \\ \text { PCR }+ & \text { s'GCACTTCTGTTTCCCC3' }\end{array}$

Cultured human rhinoviruses of several serotypes were used as positive controls and virus transport medium was used as negative controls in each assay. The appearance of a 202 base pair amplification product was taken to indicate human rhinovirus infection.

\section{CLINICAL DEFINITIONS AND DATA ANALYSES}

Episodes were classified clinically as a doubtful cold, cold, subjective exacerbation of asthma, cold with asthma, and doubtful cold plus asthma (box). Changes in peak expiratory flow rate were estimated by comparing morning and evening rates during the two weeks immediately after onset of symptoms with the rates recorded on corresponding dates during the previous month. Objective evidence of asthma was obtained if there was a significant $(p<0.05$ by paired $t$ test) drop in peak expiratory flow rate (days 1-7) and the mean decrease was $\geqslant 501 / \mathrm{min}$ compared with the control period.

\section{Results}

\section{CLINICAL EPISODES}

The 138 subjects completed 7526 patient weeks of observation. Table I shows that 315 symptomatic episodes were identified in 112 subjects; five episodes were unclassified because symptoms were not recorded. Of all 315 episodes peak expiratory flow rates were available in 310 , and 84 had objective evidence of an asthma exacerbation with $a \geqslant 50 \mathrm{1} / \mathrm{min}$ reduction in mean peak expiratory flow rate through days 1-7.

\section{LABORATORY FINDINGS}

Specimens were available for diagnosis in $229(73 \%)$ of the 315 episodes. Missing specimens (86 episodes) occurred when volunteers failed to report symptoms and episodes occurred during certain holidays, notably Christmas and the New Year, or a period of travel.

\section{Rhinoviruses}

Table II shows that human rhinovirus cytopathic effect was seen in $14(8 \%)$ of 181 nose and throat swabs taken during the acute infection tested. The identity of the viruses was confirmed by their acid lability and temperature sensitivity. None of 101 swabs taken in the convalescent period or 13 swabs taken at baseline and routine showed the cytopathic effects. All 229 acute swabs were tested by human rhinovirus seminested reverse transcriptase polymerase chain reaction; $76(33 \%)$ gave a positive result, including all 14 swabs positive on cell culture (table II). Because tests based on the polymerase chain reaction are particularly susceptible to false positive results due to contamination, ${ }^{16}$ 29 convalescent and 61 baseline and routine swabs 
TABLE I-Clinical classification of 315 symptomatic episodes in asthmatic subjects

\begin{tabular}{lcc}
\hline & $\begin{array}{c}\text { No of } \\
\text { episodes }\end{array}$ & $\begin{array}{c}\text { No with mean decrease in } \\
\text { PEFR } \geqslant 50 \text { V } \text { min }^{\star}\end{array}$ \\
\hline Colds plus asthma & 223 & 60 \\
Asthma & 35 & 14 \\
Colds & 27 & \\
Doubtful colds plus asthma & 22 & 8 \\
Doubtful colds & 3 & 2 \\
Unclassified & 5 & \\
\hline
\end{tabular}

*Peak expiratory flow rates were not available for one unclassified episode and four episodes of colds with asthma.

TABLE II-Comparison of cell culture and polymerase chain reaction for identification of human rhinoviruses in nose and throat swabs from patients with symptoms of asthma or colds, or both

\begin{tabular}{lllll}
\hline \multicolumn{3}{c}{ Polymerase chain reaction } & \\
\cline { 2 - 5 } & $\begin{array}{c}\text { Positive } \\
\text { results }\end{array}$ & $\begin{array}{c}\text { Negative } \\
\text { results }\end{array}$ & NT & Total \\
\hline
\end{tabular}

\begin{tabular}{|c|c|c|c|c|}
\hline \multicolumn{5}{|c|}{ Acute specimens } \\
\hline Cell culture: & & & & \\
\hline Positive results & 14 & 0 & 0 & 14 \\
\hline Negative results & 62 & 105 & 0 & 167 \\
\hline NT & 0 & 48 & 0 & 48 \\
\hline Total & 76 & 153 & 0 & 229 \\
\hline \multicolumn{5}{|c|}{ Convalescent specimens } \\
\hline \multirow{4}{*}{$\begin{array}{l}\text { Cell culture: } \\
\text { Positive results } \\
\text { Negative results } \\
\text { NT }\end{array}$} & & & & \\
\hline & 0 & 0 & 0 & \\
\hline & 3 & 26 & 72 & 101 \\
\hline & 0 & 0 & 86 & 86 \\
\hline Total & 3 & 26 & 158 & 187 \\
\hline \multicolumn{5}{|c|}{ Baseline and routine specimens } \\
\hline Cell culture: & & & & \\
\hline Positive results & 0 & 0 & 0 & \\
\hline Negative results & 0 & 15 & 18 & 33 \\
\hline NT & 0 & 46 & 469 & 515 \\
\hline Total & 0 & 61 & 487 & 548 \\
\hline
\end{tabular}

$\mathrm{NT}=$ not tested.

were also tested by the seminested severe transcriptase polymerase chain reaction. These additional swabs were tested together with swabs from this and other studies and transport medium controls, and the identity of the samples was not known to the investigator until the testing was complete. Three $(10 \%)$ of the 29 convalescent and none of the 61 baseline and routine swabs tested gave positive results with this method.

\section{Coronaviruses}

Human coronavirus infection was identified in 36 of the $229(16 \%)$ paired serum samples (15 of type $229 \mathrm{E}$ and 21 of type OC43).

\section{Other agents}

Complement fixation tests provided evidence of a small number of other infections: two influenza $B$, two respiratory syncytial virus, five parainfluenza virus, and three Chlamydia sp.

Infection with a single pathogen was shown by 114 of 229 nose and throat swabs and paired serum samples, and dual infections were identified by five (table III). Eighty eight laboratory confirmed infections were in women and 31 in men. Rhinoviruses accounted for 76 $(64 \%)$ of the laboratory confirmed infections, and coronaviruses accounted for a further $36(30 \%)$. There was no significant difference in the mean time from onset of symptoms to specimen collection between episodes in which pathogens were identified ( 58 hours) and those in which none were found (63 hours) (Mann-Whitney test, $\mathrm{p}>0.75$ ). Laboratory confirmed infections were associated with the clinical classification $\left(\chi^{2}\right.$ analysis, $\left.\mathrm{p}<0.01\right)$; thus for 227 episodes providing symptoms and laboratory specimens, pathogens were identified in $57 \%(111 / 196)$ of colds and colds with asthma, 29\% (5/17) of doubtful colds and doubtful colds with asthma, and $14 \%(2 / 14)$ of those with asthma symptoms only.

EFFECT OF INFECTIONS ON ASTHMA SYMPTOMS AND FLOW RATE

Symptoms of tightness, wheeze, and breathlessness were experienced during $72 \%, 65 \%$, and $70 \%$ respectively of laboratory confirmed acute respiratory infections. Peak expiratory flow rates were available for 115 of the 119 laboratory confirmed infections; 27 $(24 \%)$ were associated with a mean decrease in flow rate of $\geqslant 50 \mathrm{~V} / \mathrm{min}$ throughout the seven days after onset of symptoms, and $55(48 \%)$ had a mean decrease of $\geqslant 25 \mathrm{l} / \mathrm{min}$.

EPISODES WITH $\geqslant 50$ L/MIN MEAN DECREASE IN FLOW RATE

There were 84 clinical episodes with objective evidence of an exacerbation. In $60(71 \%)$ there were symptoms of colds with asthma. Diagnostic specimens were available for 61 of the 84 episodes. Twenty seven $(44 \%)$ of the 61 subjects had laboratory confirmed acute respiratory infections (16 human rhinovirus, four human coronavirus OC43, three parainfluenza, and one each of influenza $B$, respiratory syncytial virus, chlamydia, and dual infection with rhinovirus and coronavirus 229E; table III); these infections occurred in 10 men and 17 women.

TABLE III-Non-bacterial upper respiratory tract infections associated with mean decrease in peak expiratory flow rate $\geqslant 50 \mathrm{Vmin}$

\begin{tabular}{lcc}
\hline Pathogen & $\begin{array}{c}\text { Total No of } \\
\text { infections }\end{array}$ & $\begin{array}{c}\text { No }(\%) \text { of infections with } \geqslant 50 \text { V/min } \\
\text { mean decrease in PEFR }\end{array}$ \\
\hline HCV OC 43 & $19^{\star}$ & $4(22)$ \\
HCV 229E & 12 & 0 \\
HRV & $73 \dagger$ & $16(23)$ \\
Influenza B & 2 & 1 \\
RSV & 1 & 1 \\
Parainfluenza & 4 & 3 \\
Chlamydia psitacci & 3 & 1 \\
Dual infection & 5 & 1 \\
\hline Total & 119 & $27(23.5)$ \\
\hline
\end{tabular}

$\mathrm{HCV}=$ human coronaviruses; $\mathrm{HRV}=$ human rhinovirus; RSV $=$ - respiratory synctial virus.

^Peak flow for one episode not available.

†Peak flows for three episodes not available.

In $24(71 \%)$ of the 34 episodes in which viruses were not identified the subjects had symptoms of colds with asthma. Episodes with and without laboratory confirmed infection showed comparable decreases in peak expiratory flow rate during the 14 days after onset of symptoms (figure) and were similar in terms of consultations with general practitioners ( $49 \%$ overall), and use of oral steroids $(38 \%)$, nebulisers $(21 \%)$, and antibiotics $(33 \%)$

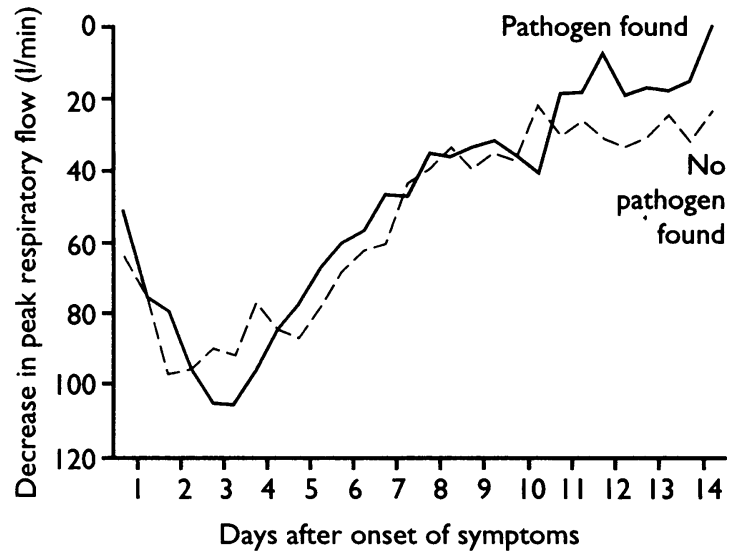

Mean daily decrease in peak expiratory flow rate for episodes with objective evidence of asthma exacerbations with and without findings of pathogens 


\section{Discussion}

An association between acute respiratory infections and asthmatic attacks in adults has been noted by others and in our previous studies ${ }^{10}{ }^{17}$ but, as no large longitudinal studies in adults have focused on both asthmatic events and upper respiratory infections and used a range of diagnostic techniques, the particular importance of respiratory viruses in adult asthmatic attacks has escaped recognition.

We identified viruses in $57 \%$ of subjects with symptomatic colds by adding rhinovirus seminested reverse transcriptase polymerase chain reaction and coronavirus ELISA to more conventional means of diagnosis. This is similar to the diagnostic rates of $51 \%$ and $59 \%$ for adults with colds in our previous studies which used polymerase chain reaction and coronavirus ELISA. ${ }^{11}$ The majority $(64 \%)$ of viruses identified were rhinoviruses. Because tests based on the polymerase chain reaction are particularly susceptible to false positive results due to contamination, we were careful to identify any possible sources of contamination and used appropriate methods to eliminate them. This included the use of separate sets of pipettes for reagents, samples, and products; the use of aerosol resistant pipette tips; and carrying out the various stages in the tests in different areas of the laboratory. Transport medium controls included in every assay gave no products after extraction, reverse transcription, and amplification. Similarly, none of 61 nose and throat swabs taken at baseline or routinely gave a positive result. These observations confirm and extend our previous negative findings with coded specimens from healthy controls. ${ }^{11}$

The subjects in this study were enrolled from the community ( $43 \%)$, general practice $(32 \%)$, and hospital $(25 \%)$, and it was our intention that the study population be representative of young adults with asthma in the general population. However, there were twice a many women as men, and $38 \%$ of the volunteers had been admitted to hospital with an asthma attack, indicating that the trial population was skewed with both more women and more subjects with a history of severe or unstable asthma than in the general asthmatic population. Our subjects were stable on recruitment, with a mean peak expiratory flow rate of $94.6 \%$ predicted. Laboratory confirmed respiratory infections were no more common in women than men and, importantly, $10(37 \%)$ of the 27 objective exacerbations of asthma associated with laboratory confirmed infections occurred in men, suggesting that "severe" exacerbations related to infection are also no more common in women than in men. As the prior hospitalisation rate in the study subjects was greater than anticipated, we compared the hospitalisation rate for subjects with a laboratory confirmed infection and objective evidence of an exacerbation with the hospitalisation rate for subjects with the same decrease

\section{Clinical implications}

- Respiratory viruses have been implicated in about half the wheezing episodes in children, but in less than one fifth of such episodes in adults

- Seminested reverse transcriptase polymerase chain reaction is four to five times more sensitive than cell culture in detecting human rhino viruses, the major causative agent of the common cold

- In this study of adults with asthma about a quarter of laboratory confirmed viral and chlamydial acute upper respiratory infections were associated with mean decreases in peak expiratory flow of $\geqslant 50 \mathrm{l} / \mathrm{min}$ and half with mean decreases of $\geqslant 25 \mathrm{l} / \mathrm{min}$

- Respiratory pathogens were implicated in almost half the most severe asthma exacerbations with $\geqslant 50 \mathrm{l} / \mathrm{min}$ mean decrease in peak expiratory flow in peak expiratory flow rate but no pathogen identified. There was no difference in the two rates (data not shown). Thus, it seems unlikely that the subjects' high rate of prior hospitalisation biased the results with respect to the identification of viruses in exacerbations of asthma.

Our findings that $80 \%$ of subjective asthma exacerbations occurred with symptomatic colds and that $89 \%$ of symptomatic colds were associated with symptoms of asthma suggest that acute respiratory infections are as commonly linked to exacerbations in adults as they are in children..$^{2-5}$ To examine this relation further we focused on the more severe episodes with objective evidence of an exacerbation-these episodes were associated with mean decreases in peak expiratory flow rate of about $100 \mathrm{l} / \mathrm{min}$ on days 2 and 3 and led $49 \%$ of patients to consult their general practitioner and $38 \%$ to use oral steroids. We identified non-bacterial pathogens, predominantly viruses, in $44 \%$ of these exacerbations, a rate similar to that of $36 \%$ found by Beasley et al in severe exacerbations in New Zealand, but considerably greater than the rate of $5 \%$ for episodes not identified as severe, ${ }^{8}$ and $10 \%$ and $19 \%$ for all exacerbations in two other studies. ${ }^{67}$ In our study, $24 \%$ of laboratory confirmed infections were associated with mean decreases in peak expiratory flow rate $\geqslant 50 \mathrm{l} / \mathrm{min}$ through days 1 to $7 ; 48 \%$ had mean decreases of $\geqslant 25 \mathrm{l} / \mathrm{min}$; and chest tightness, wheeze, and breathlessness were experienced during $72 \%$, $65 \%$, and $70 \%$, respectively, of laboratory confirmed infections. Beasley et al found that 10 of 30 laboratory confirmed respiratory infections (all caused by viruses) were associated with a severe attack and that $18(60 \%)$ were associated with exacerbations. ${ }^{8}$

Our laboratory's diagnostic rate for viruses in colds and asthma exacerbations was much higher than previous studies (Beasley et al, for example, identified viruses in $17 \%$ of 182 episodes with clinical respiratory infection ${ }^{8}$ ) but was still not as high as might be expected on the basis of symptoms. This may be due to several factors-virus isolation rates seem to be lower in adults than in children, ${ }^{12}$ possibly owing to decreased virus shedding; the specimens from swabs in our study were not tested for viral antigens by immunofluorescence or enzyme immunoassay; and we used complement fixation tests for pathogens other than rhinoviruses and coronaviruses. Despite these limitations our tests linked influenza, respiratory syncytial virus, parainfluenza, and Chlamydia sp to the more severe exacerbations of asthma, and we speculate that more sensitive tests will find these and other non-bacterial pathogens to have a much greater role than our results suggest. Conceivably these agents were involved in the objective asthma episodes for which no pathogens were identified despite there being symptoms of a cold.

In evaluating the results of this and previous studies in adults, consideration must be given to the subjects and study design. Hudgel et al and Beasley et al recruited all their patients from hospital outpatient departments and an allergy clinic, raising the possibility that the airways disease was more severe or less stable than in our subjects. ${ }^{78}$ Huhti et al studied only patients admitted to hospital during an exacerbation. ${ }^{6}$ Thus of all the studies carried out to date ours is the most representative of young adults with asthma in the general population.

Respiratory viral infections often impair small airways function for several weeks in otherwise normal subjects; these abnormalities are not detected by routine spirometry. ${ }^{18-23}$ We reasoned that some asthmatic patients with acute respiratory infections might have modest decreases in breathing capacity lasting several weeks and rarely coming to medical attention. Thus rather than focus on a single abnormality in pulmonary function to define an exacerbation, 
as in previous studies, ${ }^{78}$ we compared peak expiratory flow rates over seven day periods during respiratory episodes and control periods. By doing this we may have failed to recognise brief asthma exacerbations with modest decreases in peak expiratory flow rate, but we were less likely to include as exacerbations variability in airflow related to poorly controlled asthma.

None of the previous studies in adults tested for coronaviruses, and Huhti et al did not culture for rhinoviruses. ${ }^{6}$ In our study, identifications of rhinoviruses by seminested reverse transcriptase polymerase chain reaction and coronaviruses by ELISA improved the diagnosis of both viruses and enabled us to show that they are important causes of respiratory disease leading to exacerbations of asthma in adults as well as in children. ${ }^{242425}$ Given the far better performance of polymerase chain reaction than conventional diagnostic techniques, the newer molecular methods should greatly facilitate research in this important area.

This work was in part supported by the British Lung Foundation and the Cystic Fibrosis Trust. We thank Mrs L Jacklin for excellent technical assistance; Drs J Wales, J B Cookson, M Morgan, M Stern, J Jolleys, M Shanks, G Prowse, G Cook, $\mathrm{K}$ Baker, and J H Turner for access to their patients; Mrs M Emmerson for help in following up volunteers; Dr M Stern for helpful comments and support; and especially the volunteers, without whom this work would not have been possible.

1 Minor TE, Baker JW, Dick EC, DeMeo AN, Ouellette JJ, Cohen M, et al.

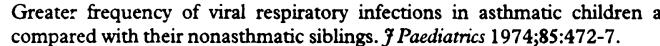

2 Minor TE, Dick EC, Baker JW, Ouellette JJ, Cohen M, Reed CE. Rhinovirus and influenza type A infections as precipitants of asthma. Am Rev Resp Dis
and and influenza type

3 McIntosh K, Ellis EF, Hoffman LS, Lybass TG, Eller J, Fulginiti VA. The association of viral and bacterial respiratory infections with exacerbations of wheezing in young asthmatic children. Pediatrics 1973;82:578-90.

4 Minor TE, Dick EC, DeMeo AN, Ouellette J, Cohen M, Reed CE. Viruses as precipitants of asthmatic attacks in children. $¥ A M A$ 1974;227:292-8.

\section{Use of chaperones by general practitioners}

\section{Arie Speelman, James Savage, Mariike Verburgh}

The Surgery, Staithe Road, Ludham, Norfolk NR29 5AB

Arie Speelman, trainee general practitioner

James Savage, general practitioner Marijke Verburgh, trainee general practitioner

Correspondence to: Dr Speelman.

$B M \Im$ 1993;307:986-7
5 Horn MEC, Reed SE, Taylor P. Role of viruses and bacteria in acute wheezy ronchitis in childhood: a study of sputum. Arch Dis Child 1979;54:587-92.

6 Huhti E, Mokka T, Nikoskelainen J, Halonen P. Association of viral and mycoplasma infections with exacerbations of asthma. Ann Allergy 1974;33:

7 Hudgel DW, Langston L, Selner JC, McIntosh K. Viral and bacterial infections in adults with chronic asthma. Am Rev Resp Dis 1979;120:393-7.

8 Beasley R, Coleman ED, Hermon Y, Holst PE, O'Donnell TVO, Tobias M. Viral respiratory tract infection and exacerbations of asthma in adult patients. Thorax 1988;43:679-83.

9 Nicholson KG, Baker DJ, Farquhar A, Hurd D, Kent J, Smith SH. Acute upper respiratory tract viral illness and influenza immunization in homes for the elderly. Epidemiol Infect 1990;105:609-18.

10 Wiselka MJ, Nicholson KG, Kent J, Cookson JB, Tyrrell DAJ. Prophylactic intranasal alpha-2 interferon and viral exacerbations of chronic respiratory disease. Thorax 1991;46:706-11.

11 Ireland DC, Kent J, Nicholson KG. Improved detection of rhinovirus in nasal and throat swabs by semi-nested RT-PCR. $\mathcal{F}$ Med Virol 1993;40:96-101.

12 American Thoracic Society. Definitions and classification of chronic bronchitis, asthma, and pulmonary emphysema. Am Rev Resp Dis 1962;85:762-8.

13 Beare AS, Reed SE. The study of antiviral compounds in volunteers. In: Oxford JS, ed. Chemoprophylaxis and virus infections of the respiratory tract. Vol 11. Cleveland: CRC Press, 1977:27-76.

14 Kraaijeveld CA, Reed SE, Macnaughton MR. Enzyme-linked immunosorbent assay for detection of antibody in volunteers experimentally infected with human coronavirus 229E. 7 Clin Microbiol 1980;12:493-7.

15 Don RH, Cox PT, Wainwright BJ, Baker K, Mattick JS. "Touchdown" PCR to circumvent spurious priming during gene amplification. Nucleic Acids Research 1991;19:4008.

16 Lo Y-MD, Mehal WZ, Fleming KA. False-positive results and the polymerase chain reaction. Lancet 1988;ii:679.

17 Wiselka MJ, Kent J, Nicholson KG, Stern M. Influenza and asthma. Lancet 1992;339:367-8.

18 Johanson WG, Pierce AK, Sanford JP. Pulmonary function in uncomplicated influenza. Am Rev Resp Dis 1969;100:141-6.

19 Picken J, Niewohner DE, Chester EM. Prolonged effects of viral infections of the upper respiratory tract upon small airways. Am f Med 1972;52:738-46.

20 Horner GJ, Gray FD. Effect of uncomplicated, presumptive influenza on the diffusing capacity of the lung. Am Rev Resp Dis 1973;108:150-5.

21 Fridy WW, Ingram RH, Hierholzer JC, Coleman MT. Airway function during mild viral respiratory illness. Ann Intern Med 1974;80:150-5.

22 Blair HT, Greenberg SB, Stevens PM, Bilunos PA, Couch RB. Effects of rhinovirus infection on pulmonary function of healthy human volunteers. Am Rev Resp Dis 1976;114:95-102.

23 Hall WJ, Hall CB. Respiratory syncytial virus infection in adults: clinical, virologic, and serial pulmonary function studies. Ann Intern Med 1978;88: 203-5.

24 Mertsola J, Ziegler T, Ruuskanen O, Vanto T, Koivikko A, Halonen P. Recurrent wheezy bronchitis and viral respiratory infections. Arch Dis Child 1991;66:124-9.

25 Lambert HP, Stern $\mathrm{H}$. Infective factors in exacerbations of bronchitis and asthma. $B M \mathcal{F} 1972$;iii:323-7.

(Accepted 17 August 1993)

without a chaperone. Their comments generally suggested that they had never thought it necessary to have a chaperone present; some said that it had never crossed their minds.

In all, 181 questionnaires were returned by the male doctors, the mean age of whom was $42 \cdot 8$ years. Ninety eight worked in rural practices. Only two doctors did not have a practice nurse available. Many used a chaperone with young patients. Other reasons for use included fear of litigation (41), the doctor's knowledge of the patient (13), and intuition (22). The main reasons given for not using a chaperone were too time consuming, impractical, unnecessary, and not beneficial to the doctor-patient relationship. Sixty six thought that the use of a chaperone could damage the doctor-patient relationship, while 80 thought the opposite. Thirty one male doctors felt uncomfortable and 129 felt comfortable without a chaperone. We found no correlation between the frequency of use of chaperones and the practice size or doctor's age.

Male doctors mostly used practice nurses (135) as chaperones, but some also used receptionists (40), dispensers (one), and practice managers (two).

A questionnaire was sent to 200 randomly selected male and to all 60 female general practitioners listed by Norfolk Family Health Services Authority. It asked about doctors' characteristics and their use of chaperones when examining patients of the opposite sex-for example, to take a cervical smear or assess testicular swelling. The results were analysed by computer with the Epi Infor version 5 statistical program separately according to the doctor's sex and are shown in the table.

Fifty one questionnaires were returned by the female doctors. Forty seven felt comfortable examining

Use of chaperones by general practitioners according to sex of doctor. Values are numbers (percentages) of doctors

Never Rarely Sometimes Always

\begin{tabular}{lrrrr}
\hline Female $(\mathrm{n}=51):$ & & & & \\
Intend to use chaperone & $38(75)$ & $10(20)$ & $3(6)$ & 0 \\
Intend to offer chaperone & $40(78)$ & $8(16)$ & $3(6)$ & 0 \\
Male $(\mathrm{n}=181):$ & & & & \\
Intend to use chaperone & $38(21)$ & $79(44)$ & $35(19)$ & $29(16)$ \\
Intend to offer chaperone & $62(34)$ & $57(32)$ & $34(19)$ & $24(13)$ \\
\end{tabular}

